\title{
O Pibid e a trajetória profissional de licenciados em Química
}

\section{The PIBID and the professional trajectories of Chemistry teachers}

\section{EI PIBID y la trayectoria profesional de licenciados en Química}

Bruno Ferreira dos Santos, doutor em Ciências Sociais e Humanas pela Universidad Nacional de Quilmes (UNQ), Argentina, professor nos cursos de graduação em Química e na Pós-graduação em Educação Científica e Formação de Professores de Ciências e Matemática, na Universidade Estadual do Sudoeste da Bahia (Uesb), campus de Jequié. E-mail: bf-santos@uol.com.br.

Jucimara de Jesus Moraes, licenciada em Química pela Universidade Estadual do Sudoeste da Bahia (Uesb), campus de Jequié e exbolsista do Pibid. E-mail: jucimaraquimica@hotmail.com.

\section{Resumo}

Neste artigo são apresentados os resultados de pesquisa realizada com egressos de um curso de licenciatura em Química que foram bolsistas do Programa Institucional de Bolsas de Iniciação à Docência (Pibid). Os recém-graduados foram entrevistados por meio de questionários e entrevistas semiestruturadas. Seu objetivo principal foi o de conhecer os fatores que incidem sobre o que define sua trajetória profissional e as relações entre sua participação nesse programa de iniciação à docência e as escolhas profissionais. Os dados levantados foram analisados por meio da Teoria Fundamentada. A análise dos dados permitiu a elaboração de uma interpretação sobre as escolhas profissionais dos licenciados, cuja opção primordial pela educação permanente está representada pela formação como pesquisador, e a 
atuação como docente é postergada para o futuro ou como um projeto alternativo em suas trajetórias profissionais.

Palavras-chave: Trajetória Profissional. Licenciatura em Química. Formação Docente. Pibid.

\section{Abstract}

In this article we present the results of a research study made with graduates of a course of teacher training in chemistry which were fellows of PIBID. The graduates were interviewed by questionnaires and semi-structured interviews. Our main aim was to identify the factors that define professional trajectories of the graduates and also to know the relationships between their participation in this program of initiation to teaching and their professional choices. Our data were analyzed by using grounded theory. Through this analysis we could elaborate an interpretation about the professional choices of newly certified teachers, whose primary option for permanent education is represented by formation as a researcher. Acting as a teacher is postponed for the future or is taken as an alternative project in their professional trajectories.

Keywords: Professional Trajectory. Teacher Training in Chemistry. PIBID.

\section{Resumen}

Ese artículo presenta los resultados de una investigación realizada con egresos de una carrera de licenciatura en química que fueron becarios del PIBID. Los recién graduados fueron entrevistados por medio de cuestionarios y entrevistas semiestructuradas. Su principal objetivo fue conocer los factores que inciden sobre la definición de sus trayectorias profesionales y también conocer las relaciones entre su participación en este programa y las elecciones profesionales. Los datos fueron analizados con la teoría fundamentada. Por medio de ese análisis 
elaboramos una interpretación sobre las elecciones profesionales de los recién graduados, cuya opción primera por la educación permanente está representada por la formación como investigador, mientras la actuación como docente es postergada para el futuro o tomada como un proyecto alternativo en sus trayectorias profesionales.

Palabras clave: Trayectoria Profesional. Licenciatura en Química. Formación Docente. PIBID.

\section{Introdução}

O Programa Institucional de Bolsas de Iniciação à Docência (Pibid) é considerado um programa inédito de formação inicial de professores para a educação no Brasil (OLIVEIRA, 2012). O Pibid, por estabelecer uma ponte entre a escola e a universidade, proporciona a interação entre ambas as instituições, o que, por sua vez, oferece um grande potencial para a formação dos licenciandos, pois viabiliza uma experiência com a realidade do trabalho docente capaz de se dar desde o início da graduação'. Supõe-se, entre outras coisas, que essa imersão do licenciando no ambiente escolar o capacite com maior autonomia na profissão que exercerá futuramente. O Pibid também oferece uma oportunidade de formação continuada para os professores da escola básica que são supervisores do programa, e isso pode impactar diretamente na educação de seus estudantes.

Criado em um contexto de demanda pela universalização do ensino médio, o Pibid, entre outros objetivos, busca contribuir para suprir a carência de profissionais da educação para esse nível de ensino. Na área de Ciências, aí incluídas a Física e a Química, a necessidade de professores há tempos vem sendo anunciada como muito maior do que a quantidade de profissionais que as instituições de nível superior ofertam à sociedade (GATTI; BARRETO, 2009). A premissa básica do Pibid em relação à demanda de professores para a educação básica é a de, ao possibilitar ao licenciando o contato com a escola e com a docência, despertar-Ihe interesse e desejo de continuar na profissão uma vez graduado. Entretanto, além do desinteresse dos estudantes

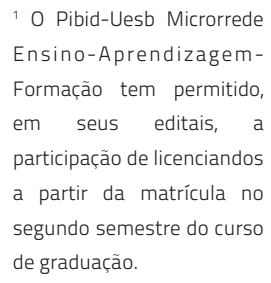


do ensino médio em optar por Química ou Física por serem essas disciplinas normalmente consideradas difíceis, muitas vezes tais cursos apresentam a modalidade de graduação em bacharelado ao lado da licenciatura, o que pode agravar a falta de interesse pela formação como docente nessas áreas.

A maior "inclinação" dos estudantes pelos cursos de bacharelado tem sido explicada em termos de status. Para Roseli Schnetzler (2000), renomada investigadora em educação química no país, a formação docente "continua subestimada, deixando de ser reconhecida em sua importância, pois esse curso, em sua essência, carrega a forte marca da formação do bacharel, considerado de prestígio acadêmico e científico" (p. 14). Considerando que a graduação em Química na Universidade Estadual do Sudoeste da Bahia (Uesb), Campus de Jequié, traz as marcas dessa dualidade, uma vez que oferta as duas modalidades de formação, cabe perguntar: de qual forma as experiências adquiridas no Pibid podem influenciar a escolha profissional dos licenciados em Química? De que modo a experiência como bolsista contribui para a definição da trajetória profissional dos egressos da licenciatura? Participar de um programa que incentiva a docência garantirá que o licenciado opte por seguir a carreira docente? Por ser o Pibid um programa inédito, como já dito, tais questões merecem ser investigadas, pois as respostas a essas perguntas ajudam a compreender melhor o alcance e as limitações da iniciativa.

Este trabalho, originado de pesquisa realizada para uma monografia de conclusão de curso, tem como objetivo principal compreender os fatores que influenciaram um grupo de egressos da licenciatura em Química da Uesb que foram bolsistas do Pibid por meio do subprojeto Ensino de Química e Sociedade em relação às escolhas profissionais e as relações que estabelecem entre sua participação no programa e essas escolhas. Os dados coletados nesta pesquisa foram interpretados à luz do modelo oferecido pela Teoria Fundamentada ou Grounded Theory, método de análise qualitativa desenvolvido por Glaser e Strauss (STRAUSS; CORBIN, 2008). Os autores esperam contribuir com o importante debate sobre a formação do professor de Química, a carreira profissional dos licenciados e o Pibid, um elemento novo que se insere nessa discussão. 


\section{Situando o problema}

O Pibid é um programa da Coordenação de Aperfeiçoamento de Pessoal de Nivel Superior (Capes) fundamentado inicialmente pelo Decreto $n^{\circ}$ 7.219/2010 e transformado em uma política pública permanente associada à formação de professores, com base nas Leis $n^{\circ}$ 12.796/2013 e $n^{\circ}$ 13.005/2014 (BRASIL, 2013, 2014). O programa surgiu no âmbito da ampliação das ações da Capes, quando esta agência pertencente ao Ministério da Educação e tradicionalmente associada à pós-graduação se voltou para a formação inicial dos professores da educação básica, durante o segundo governo Lula (2007-2010). Suas diretrizes se orientam com base em diagnósticos sobre a formação de professores no Brasil, como a insuficiência de licenciados interessados em atuar na docência escolar ou a qualidade dessa formação.

De acordo com Sá (2009), o desinteresse e a falta de entusiasmo por parte de alguns estudantes da licenciatura pela profissão docente têm motivado a realização de pesquisas que discutem as causas para esse quadro desalentador com respeito à formação de professores. Mas, segundo a mesma autora, o Pibid pode significar uma mudança nesse quadro, pois o programa é "apontado como um elemento motivador para a atuação e permanência na carreira docente" (SÁ, 2014, p. 48), de acordo com um dos resultados de pesquisa realizada com bolsistas. Weber et al. (2013) encontram um resultado semelhante em pesquisa com bolsistas e ex-bolsistas do programa, em que o contato com o ambiente escolar proporcionado pelo Pibid confirma, para muitos, a escolha pela profissão docente. No entanto, essa "percepção positiva” do trabalho do professor de Química nem sempre se reflete nas escolhas dos egressos: alguns deles preferem cursar outra graduação, por exemplo, uma vez que concluem a licenciatura em Química (WEBER et al., 2013).

A formação de professores de Química em um contexto institucional que apresenta grande ênfase na pesquisa científica nessa área foi investigada por Adriana Rossi, professora da Universidade Estadual de Campinas, estado de São Paulo. Trata-se, neste caso, de licenciandos que "estão inseridos num contexto acadêmico com forte ênfase na pesquisa química, diversas opções de bolsas de iniciação 
científica e estágios remunerados e, em geral, cursam a licenciatura paralelamente ao bacharelado ou bacharelado tecnológico" (ROSSI, 2013, p. 261). Com base nas respostas apresentadas pelos bolsistas do Pibid dessa instituição a um pequeno questionário, a autora informa que, para uma parte significativa dos bolsistas, "vivenciar o cotidiano das escolas públicas com todas as suas dificuldades e a falta de valorização salarial pode impedir sua opção pelo magistério" (ROSSI, 2013, p. 261). De acordo com a autora, tal quadro não poderá ser superado por ajustes no programa, pois depende mais de transformações no cenário externo associadas à inserção profissional e às expectativas dos licenciados com respeito ao seu futuro. Não obstante, Rossi argumenta que “todas as propostas coerentes que visem estimular a opção profissional pela licenciatura devem ser estimuladas, e o Pibid cumpre esse objetivo de forma plena” (p. 262).

O Pibid também tem sido avaliado como elemento que contribui para a permanência dos estudantes bolsistas nos cursos de licenciatura, especialmente naquelas regiões menos favorecidas economicamente, como o Nordeste brasileiro (SILVA; MARTINS, 2014). O diagnóstico é o de que a bolsa distribuída aos licenciandos que participam do programa os retira do mercado de trabalho onde eles exercem alguma atividade remunerada e de que, na maioria das vezes, dificulta a sua dedicação aos estudos, contribuindo para a alta evasão apresentada na licenciatura em Química, especialmente quando ofertada no turno noturno.

A contribuição positiva do Pibid para as licenciaturas é verificada na ampla maioria dos trabalhos publicados sobre esse programa, com destaque para a fixação dos alunos nos cursos, pelo maior interesse deles pela carreira docente, pela articulação entre as dimensões teórica e prática na formação docente propiciada pela configuração particular dos subprojetos etc. O êxito do programa o levou a ser considerado como "um dos mais estruturantes e importantes na valorização da carreira docente" (CLÍMACO; NEVES; LIMA, 2012, p. 192). Como já destacado anteriormente, o caráter ainda inédito do Pibid deve estimular a produção de pesquisas que prossigam avaliando a sua contribuição para as licenciaturas, especialmente com respeito àquele que é o seu objetivo principal: o estímulo à carreira docente. 
Quando se discute formação docente no Brasil, a noção de identidade aparece como central para o entendimento da constituição dos sujeitos por meio de políticas culturais, como são caracterizadas as políticas curriculares para a formação docente. No entanto, de acordo com Rosa et al. (2008), a identidade profissional docente está atravessada por discursos oriundos de campos em disputa, o que deriva das noções de identidades múltiplas ou fragmentadas, que, no caso do profissional químico, se produzem por meio de diferentes interpelações - o químico como bacharel, como tecnólogo e como professor. Considerando a fluidez da noção de identidade e o fato de a amostra aqui utilizada ser constituída por recém-formados, este trabalho optou por explorar o conceito de trajetória profissional. Nesse caso, a presente pesquisa se aproxima dos estudos sobre os egressos, tendo como base a análise das trajetórias profissionais, como a pesquisa desenvolvida por Amorim (2014). Segundo Schwartzman e Castro (1991), esse tipo de estudo:

[...] recupera, de fato, várias questões do estudo de alunos, particularmente as ligadas à qualidade do ensino e adequação dos currículos à situação profissional; a origem dos projetos profissionais e a consistência desses em relação à situação profissional de fato; o impacto da formação universitária sobre atitudes, círculo de relação, qualificações formais e informais, e sobre o desempenho e a satisfação com a carreira profissional (p. 15).

Durante a sua formação, o licenciando pode se deparar com diferentes experiências, as quais poderão influenciar de diferentes maneiras sua trajetória profissional. Portanto, quando se discute trajetória profissional, deve-se procurar conhecer as experiências adquiridas e as escolhas feitas pelos licenciados antes ou durante sua graduação, como a escolha do curso, os professores que tiveram, os projetos de que participaram e que desenvolveram, os estágios, as experiências em programas de iniciação, enfim as escolhas que dizem respeito à futura trajetória profissional e que podem ser definidas por uma infinidade de experiências vivenciadas por esses estudantes durante ou mesmo antes de sua graduação. 


\section{Os sujeitos e os métodos da pesquisa}

Para responder às perguntas relacionadas com os objetivos que originaram este estudo, foi desenvolvida uma pesquisa qualitativa, inicialmente por meio de um questionário contendo seis questões abertas, o qual foi respondido por seis ex-bolsistas do Pibid Ensino de Química e Sociedade, egressos da licenciatura em Química da Uesb, Campus de Jequié, no ano letivo de 2013. O questionário foi enviado para os ex-bolsistas por e-mail e foram respondidos e devolvidos pelo mesmo meio de comunicação². Com base em uma primeira análise das respostas ao questionário, foi elaborado um segundo roteiro para uma entrevista semiestruturada, que foi aplicada a quatro dos ex-bolsistas, com o objetivo de aprofundar e validar a análise com outros tipos de dados. Essas entrevistas foram individuais, gravadas em equipamento de áudio e posteriormente transcritas para análise. Todas as questões respondidas pelos egressos foram elaboradas de maneira que os levassem a falar sobre suas experiências durante a graduação e sobre suas escolhas profissionais.

Os sujeitos da pesquisa são os licenciados em Química e exbolsistas do Pibid Ensino de Química e Sociedade, aqui nomeados Clara, Carol, Antônia, João, Maria e Ana³. Essa amostra só é considerada representativa de um ponto de vista qualitativo, pois constituída a partir dos casos disponíveis a que o pesquisador tem acesso, e não é representativa de um ponto de vista estatístico. A idade dos pesquisados está entre 23 e 27 anos, e todos eles iniciaram sua trajetória como bolsistas no referido subprojeto em agosto de 2012 e permaneceram até agosto de 2013, quando concluíram o curso de licenciatura em Química da Uesb, Campus de Jequié. Todos demonstraram interesse e boa vontade em responder ao questionário inicial, e quatro deles se dispuseram a relatar suas experiências por meio de uma entrevista semiestruturada. A etapa de coleta de dados ocorreu entre os meses de abril e junho do ano de 2014.

O subprojeto Pibid Ensino de Química e Sociedade iniciou

20 questionário foi enviado a nove ex-bolsistas no total. ${ }^{3}$ Nomes fictícios. 
universidade ao Edital Capes $n^{\circ}$ 11/2012. Foram selecionados para atuar como bolsistas 20 estudantes da licenciatura em Química. Um dos requisitos para concorrer à bolsa era o de não estar recebendo outro tipo de auxílio financeiro, como bolsa de Iniciação Científica. O curso de licenciatura em Química da Uesb, por sua vez, foi criado no ano de 1999, após a extinção da antiga licenciatura em Ciências, que habilitava licenciandos em Química e em Ciências Biológicas. A primeira turma da licenciatura em Química concluiu o curso no ano de 2004. No ano seguinte, o Campus de Jequié implantou o bacharelado em Química e o curso de mestrado em Química Analítica, cujos alunos, em sua maioria, eram egressos dos cursos de licenciatura e de bacharelado do próprio campus. A licenciatura sofreu uma reformulação curricular em 2005, de forma a adequar-se às novas diretrizes curriculares para os cursos de licenciatura em Química, estabelecidas pelo Ministério de Educação durante os anos 2000 (BRASIL, 2001). Em 2011, um curso de mestrado em Educação Científica começou a funcionar no campus, e se tornou mais uma opção de pós-graduação para os licenciandos em Química.

A análise e a interpretação dos dados tiveram por base os métodos da Teoria Fundamentada, como descritos em Strauss e Corbin (2008) e Charmaz (2009), com o objetivo de elaborar um meio de interpretar as decisões dos egressos em relação à trajetória profissional de cada um. Teoria Fundamentada significa uma "teoria que foi derivada dos dados, sistematicamente reunidos e analisados por meio de uma pesquisa" (STRAUSS; CORBIN, 2008, p. 25). A ênfase posta pelos autores da Teoria Fundamentada na relação entre a produção de teoria e os dados empíricos surge como uma reação à especulação teórica desprovida de referências à realidade social e também à pesquisa em Sociologia baseada na abordagem quantitativa (LAPERRIÈRE, 2010).

Glaser e Strauss (1967) distinguem dois tipos de teorias que podem ser geradas por meio da análise comparativa, forma de análise característica dos métodos da Teoria Fundamentada: a substantiva e a formal. A última corresponde àquele tipo de teoria desenvolvida para explicar fenômenos formais ou conceituais da pesquisa sociológica, como o estigma ou o comportamento desviante. Para os autores, ambos os tipos de teoria são considerados de alcance médio e não representam 
totalizações ou sistematizações sobre a ação ou o comportamento social. O interesse deste estudo é o de buscar desenvolver uma teoria substantiva com o objetivo de interpretar e explicar um problema específico referente a uma área particular, qual seja, as escolhas que definem a trajetória profissional de um grupo de egressos da licenciatura em Química que participaram do Pibid. A eleição da Teoria Fundamentada para esta pesquisa se justifica pelo fato de esse método ser apropriado quando a intenção "é indagar um certo tema com o objetivo de fazer emergir os processos subjacentes às afirmações dos participantes ou aos fenômenos observados" (TOZZI, 2011, p. 93).

Um aspecto importante a ser destacado é o de que quando se utiliza a Teoria Fundamentada, diferentemente de outros tipos de estudo, não se conhece de antemão a literatura relevante antes de se avançar com a pesquisa e, uma vez conhecida a literatura específica, esta não adquire um lugar destacado, e se lhe outorga o mesmo status que a outra fonte de dados (SONEIRA, 2007). Essa característica peculiar do método se justifica pelo fato de que o interesse está em criar ou propor uma nova teoria, e não em testar teorias já existentes. Dessa forma, a literatura que dialoga com a análise dos dados empíricos surge ou emerge concomitantemente com a própria análise, sem constituir um marco teórico definido a priori. Essa orientação na relação entre os dados empíricos e a literatura foi seguida nesta pesquisa.

A análise dos dados na Teoria Fundamentada inicia com a chamada microanálise, a qual visa fazer emergir as semelhanças e os contrastes entre os dados e, ao mesmo tempo, as primeiras questões endereçadas aos próprios dados (LAPARRIĖRE, 2010; TOYOS, 2014). As respostas a tais questões auxiliam na proposição das primeiras categorias e subcategorias, que podem ter origem na imaginação do pesquisador ou nos chamados códigos in vivo, conceitos empregados pelos informantes em seus próprios termos. O processo de codificação se completa com a redação de memorandos e roteiros, com o levantamento das propriedades e dimensões das categorias e subcategorias e com o desenho de diagramas. Durante a análise, algumas categorias se revelam provisórias e são substituídas por outras. Esse processo pode ser extenso e minucioso, e um relato mais fidedigno de suas 
características extrapola as dimensões de um artigo científico; portanto, são apresentados aqui os procedimentos e resultados do modo mais sintético possível.

\section{Resultados}

Dos seis egressos entrevistados, cinco estavam cursando mestrado no momento da entrevista. Clara, a única ex-bolsista que não estava em um mestrado, declarou estar atuando em área não relacionada com a Química, mas acrescentou estar se preparando para alguma seleção de mestrado em Química ou em Educação. Ela explicou o fato de estar atuando em área diferente da docência por ainda não ter havido um concurso para professor. Apenas um deles, João, afirmou estar ensinando enquanto cursa o mestrado. Quatro dos cinco ex-bolsistas estão cursando o mestrado em Química Analítica da própria Uesb, e um deles cursa um mestrado em Ciências dos Materiais em outra instituição. Chama a atenção o fato de que, apesar de o mesmo campus universitário oferecer um mestrado em Educação Científica para o qual eles também podiam concorrer a uma vaga, nenhum dos egressos tenha optado por esse curso, mas, sim, pelo de Química Analítica.

A "educação permanente" emergiu como a categoria central. Ela aparece no sentido de "continuidade dos estudos" (código in vivo), necessária para o aperfeiçoamento e o crescimento profissionais e pessoais, bem como para a realização própria. Assim, por exemplo, em resposta à questão que indaga por que o egresso optou pela ocupação a que está se dedicando neste momento, João declara estar no mestrado, buscando:

[...] o aperfeiçoamento da graduação, a obtenção de conhecimento e o melhoramento do currículo, entre outras vantagens que o título de mestre irá me possibilitar (João, aluno do mestrado em Química Analítica).

Duas outras categorias surgiram para a definição da proposição: a "formação como pesquisador" e a "atuação como docente". A “educação permanente", como citada pelos ex-bolsistas, envolve basicamente os 
cursos de pós-graduação, como o mestrado e o doutorado, que, a rigor, constituem etapas da educação superior e, dessa forma, exaram títulos acadêmicos. Entretanto, como dito anteriormente, todos os que cursam mestrado optaram pelo de Química ou de área correlata, mas não por um mestrado em Educação, o que poderia representar um aperfeiçoamento mais relacionado com a profissão docente. Duas propriedades surgem e ajudam a entender a opção dos ex-bolsistas pelo mestrado em Química ou em área correlata, como educação permanente: a preferência pela pesquisa em Química e a diversificação da formação profissional.

Por que os ex-bolsistas optam pelo mestrado em Química ou em área correlata? A preferência pela pesquisa em Química é explicada e justificada por eles por uma questão de gosto ou vocação ("Especializarme na área de pesquisa de que eu gosto", "Dei-me conta de que a pesquisa me movia e me impulsionava a seguir em frente", "Identificome com a pesquisa”, Carol, aluna do mestrado em Química Analítica; "Tenho projeto de ingressar no doutorado e me dedicar às pesquisas, porque é algo que me fascina e me faz crescer enquanto profissional", Ana, aluna do mestrado em Química Analítica; “É um meio [a área de Bioquímica] que estou descobrindo e está me fascinando", Antônia, aluna do mestrado em Química Analítica). Essa formação como pesquisador também é justificada por eles como uma diversificação da formação profissional:

\footnotetext{
"Na graduação eu me descobri professor, mas meu objetivo desde o início era me tornar um químico pesquisador; na graduação, descobri o programa de pós oferecido pela universidade e percebi a oportunidade de unificar as duas funções que o curso oferece. Com meu diploma, posso lecionar Química em qualquer lugar, mas a pós-graduação me dará oportunidade de também concorrer no mercado de trabalho como químico laboratorial” (João, aluno do mestrado em Química Analítica).
}

A ex-bolsista Ana também indica esse anseio pela diversificação: "a vontade de complementar a minha formação e crescer profissionalmente". Conta, para as inclinações dos ex-bolsistas, a cultura acadêmica que permeia as instituições formadoras de professores "em que os modos de consagração são, todos eles, referentes ao campo científico-acadêmico" (FARIA FILHO, 2014, p. 92). É no seio dessa cultura acadêmica que suas sensibilidades vão sendo forjadas. 
Segundo o sociólogo Zygmunt Bauman (2007), nos dias atuais, caracterizados por ele como um "ambiente líquido-moderno", o trabalho da educação e o da aprendizagem, para serem úteis:

"[...] devem ser contínuos e durar toda a vida. Nenhum outro tipo de educação e/ou aprendizagem é concebivel; a formação do próprio eu, ou da personalidade, é impensável de qualquer outro modo que não seja aquele contínuo e perpetuamente incompleto" (p. 13).

É esse sentido de incompletude da formação argumentado por Bauman que perpassa não somente o aspecto profissional, mas toda a existência que compreende a motivação e a necessidade da educação permanente, conforme os ex-bolsistas proclamam:

"Todo o curso motivou para a continuação dos estudos, pois acredito que o saber não finda. Enquanto existir sopro de vida, sempre há o que aprender" (Maria, aluna do mestrado em Ciências dos Materiais).

“Após a conclusão do mestrado, pretendo me engajar em uma seleção de doutorado, não pretendo parar meus estudos” (João, aluno do mestrado em Química Analítica).

A sociedade capitalista globalizada e pós-industrial demanda uma força de trabalho cada vez mais qualificada e adaptável, cuja formação se estende muito após a obtenção de um título ou diploma como o de uma graduação, de modo a afrontar um ambiente social e econômico marcado pelo impacto de câmbios acelerados. Ainda de acordo com Bauman (2007), a ideia de educação permanente se transformou de um oximoro em um pleonasmo. Estimula-se mais a capacidade de aprender (e permanecer aprendendo) do que a posse de determinado conhecimento, pois a estabilidade de um conhecimento adquirido pode inclusive tornar-se algo indesejável: "Todas as informações obtidas 'envelhecem' rapidamente e, em lugar de prover um guia confiável, podem nos deixar fora se não são prontamente deixadas de lado" (BAUMAN, 2007, p. 12)

Tais características se aproximam daquelas definidas por Gilles Deleuze (2010) como a sociedade de controle, que vem a substituir a sociedade disciplinar descrita por Michel Foucault: é o princípio de 
modulação introduzido pelas empresas, que resulta em competitividade e rivalidade, contrapondo os indivíduos entre si, e que incide sobre a educação no modo da formação permanente.

O princípio modulador do "salário por mérito" tenta a própria Educação nacional: com efeito, assim como a empresa substitui a fábrica, a formação permanente tende a substituir a escola, e o controle contínuo substitui o exame (DELEUZE, 2010, p. 225, grifo do autor).

Assim, estabelece-se de modo imperioso a necessidade de diversificar e complementar a formação como forma de inserir-se em um mercado de trabalho caracterizado pela fluidez e pela precariedade das relações.

A categoria "atuação como docente" também está constituída por duas propriedades: a docência como um projeto para o futuro e a docência como um projeto alternativo. A docência como um projeto para o futuro significa que se vislumbra o exercício da profissão em longo prazo, muito provavelmente após a conclusão dos cursos de pósgraduação:

"Gosto de ensinar e futuramente pretendo trabalhar nessa área. Após o mestrado, pretendo trabalhar como professora em uma escola ou universidade, na área de Química" (Clara, trabalhadora em outra área e aspirante ao mestrado em Química).

"Pretendo prestar alguma seleção para professor em uma universidade ou instituto federal de educação, exercendo a função de professor e pesquisador" (João, aluno do mestrado em Química Analítica).

"Eu quero ser professora e pesquisadora, porque me identifico com a pesquisa e acho que os alunos merecem uma educação de qualidade. Acredito que posso contribuir para mudar a realidade da educação brasileira. Mesmo fazendo o mestrado em Química Analítica, ainda quero ensinar, isso não me opõe a continuar na licenciatura" (Carol, aluna do mestrado em Química Analítica).

A docência como um projeto alternativo surge como possibilidade de exercê-la caso não se estivesse dedicando ao mestrado: 
"Se eu não estivesse fazendo mestrado, eu estaria ministrando aulas na rede pública ou privada de ensino, porque sou licenciada em Química e estaria estudando para fazer concursos nessa área” (Carol, aluna do mestrado em Química Analítica).

"Se eu não tivesse passado no curso de pós-graduação, por questões financeiras, com certeza, estaria lecionando em um colégio particular da cidade com o qual já tinha um vínculo antes mesmo do fim da graduação" (João, aluno do mestrado em Química Analítica).

“Estaria lecionando Química, porque já iria lecionar. Abdiquei para estudar na universidade em que o programa exige dedicação exclusiva para quem é bolsista" (Maria, aluna do mestrado em Ciências dos Materiais).

Como dito anteriormente, na Teoria Fundamentada, as categorias principais estão conectadas à categoria central. As propriedades por meio das quais se manifesta a categoria "atuação como docente" resultam da prioridade outorgada pelos ex-bolsistas à sua educação permanente. Ao priorizar a pós-graduação, os licenciados deixam de atuar em sua profissão, tornando o seu exercício um projeto para o futuro ou um projeto alternativo àquele que se encontram realizando em sua trajetória profissional. Os dados também sugerem, à semelhança do que foi observado por Amorim (2014) em sua pesquisa com egressos de um curso de licenciatura em História, que "o trabalho como professor da educação básica está sendo encarado, sobretudo, como temporário; isto é, como um posto a ser ocupado enquanto não se conquista outro melhor” (p. 47). Apesar disso, eles não deixam de relacionar a formação permanente com o exercício da docência. Em alguns casos, essa relação se dá quando eles vislumbram a docência em universidades ou institutos federais de educação - onde o exercício da profissão adquire melhores condições que nas escolas públicas. Em outros casos, eles afirmam que um curso de mestrado, mesmo que seja em Química, contribui para a sua formação docente. É o que afirma Clara:

“Eu pretendo fazer o mestrado, acho que, mesmo querendo ser professora e tendo como objetivo fazer um mestrado em uma outra área, não necessariamente em Educação, isso vai ter uma importância muito grande quando eu for para a sala de aula. Acredito que é um enriquecimento a mais, uma experiência a mais, uma formação a mais que vou obter durante o mestrado. Atualmente, não estou ensinando. Já 
terminei o curso, mas não estou ensinando. Vejo o mestrado como uma forma de me sentir mais preparada - não que eu não esteja preparada agora, mas acredito que, com o mestrado, vou ter mais confiança, sentirme mais preparada para trabalhar, mesmo que seja em outra área. Se for em educação, ótimo, é o que eu quero. Quero Educação, sim!”

Também surge uma relação mais distante entre a docência e a formação que não estabelece a mesma complementaridade entre a atuação como professor e a formação como pesquisador químico, conforme Clara destaca em sua fala. Nesse caso, os ex-bolsistas questionam sua própria formação inicial quanto à preparação para a atuação profissional proporcionada pelo curso de licenciatura:

"Acho que estou preparado para lecionar com a teoria química, mas, ainda como químico de laboratório, estou tendo de correr atrás do prejuízo, não tem jeito. Em parte, eu tive o privilégio de participar do Pibid, que foi muito enriquecedor para essa escolha como docente, mas acho que sim, que, no final das contas, o curso acaba nos formando professores de Química. Se não tivesse participado como bolsista do Pibid, faltaria mais experiência, acredito que apenas dois estágios oferecidos pela graduação em licenciatura em Química é pouco. Como teoria, sim, é como eu falei, eu me sinto pronto, porque vi a teoria muito bem vista, mas a prática ainda como docente, assim como a prática de que ainda estou precisando no mestrado, ainda é muito vaga" (João, aluno do mestrado em Química Analítica).

"Eu me sinto preparada como professora de Química. Acredito que o curso me deu embasamento suficiente para estar na licenciatura, para estar dando aula, em sala de aula. A participação no Pibid me ajudou muito na questão de lidar com os alunos na prática de sala de aula e também na questão da autonomia em sala de aula, porque só temos dois estágios na graduação. E, esses dois estágios, pelo menos para mim, não foram suficientes para lidar com os alunos, para ter maior domínio em sala de aula, diferentemente do Pibid, que já contribui, porque nele temos contato direto com o aluno" (Ana, aluna do mestrado em Química Analítica).

João considera estar adquirindo no mestrado em Química a experiência em laboratório que seu curso de licenciatura deixou a desejar, embora se sinta preparado para lecionar, especialmente após sua participação no Pibid, percepção compartilhada com Carol. Mas o sentimento de incompletude aparece tanto em Clara como em João: é 
uma formação em que sempre parece faltar algo. No caso da formação docente, segundo eles, falta o exercício da prática, algo que os estágios supervisionados não dão conta de proporcionar a contento.

Para Deleuze (2010), nas sociedades de controle "nunca se termina nada, a empresa, a formação, o serviço sendo os estados metaestáveis e coexistentes de uma mesma modulação" (p. 226). Mas, se a formação se estende por muitos anos após a obtenção do diploma de graduação devido a esse sentimento de incompletude (o "oximoro" de que nos fala Bauman), a modulação tem a ver com o exercício do “individualismo do autodesenho", relacionado com o:

(...) trabalho permanente e sustentado para converter a própria existência em um objeto estético original e criativo, uma recriação sem fim, em um movimento contínuo sobre si mesmo para desenvolver plenamente as próprias capacidades (SLOTERDIJK apud DUSSEL, 2006, p. 149).

Por isso os ex-bolsistas afirmam buscar em sua formação a realização pessoal e definir suas escolhas profissionais com base no gosto e identificar, nesse investimento, uma projeção de si mesmo. Todo o investimento que deve ser feito nesse trabalho de autodesenho, entretanto, conduz os ex-bolsistas a estenderem sua formação profissional por um período muito maior do que o expendido pelas gerações anteriores ou mesmo por jovens pertencentes a setores sociais menos favorecidos. A distribuição de bolsas pelo sistema de pósgraduação, por exemplo, contribui para esse deslocamento no tempo de ingresso em uma profissão.

Sendo a modulação de si por meio da formação profissional uma característica da fluidez da modernidade líquida em oposição à rigidez que limitava a liberdade de escolher e atuar (BAUMAN, 2006), a licenciatura em Química, devido a sua ambiguidade, parece, no fim das contas, favorecer a amplitude das escolhas dos ex-bolsistas. Nesse sentido, compreendese a afirmação de Carol no sentido de que fazer o mestrado em Química Analítica não se opõe a permanecer na licenciatura:

“O curso em si leva a pessoa a ir, sim, mais para o lado da área técnica do que a licenciatura mesmo, porque são mais as disciplinas voltadas para o 
curso de bacharelado. Durante o curso, eu tive experiência tanto na área técnica quanto na área de licenciatura, porque tive as duas iniciações, na área técnica e na iniciação à docência. E, desde o início do curso, já quis partir para a área técnica, porque estar no laboratório mexendo com reagente e pesquisando é uma coisa de que eu gosto, mas também gosto de estar na sala de aula. Então, quero fazer os dois, e acredito que não atrapalha tanto".

Nesse cenário, o Pibid aparece para os ex-bolsistas como a experiência que confirma uma das suas escolhas - a docência -, ainda que esta, como visto, não venha a se concretizar de imediato em suas trajetórias profissionais, mas permanecerá como uma opção a ser acionada em algum momento futuro:

\footnotetext{
"Quando eu entrei no Pibid, já estava convencida de que a licenciatura era o que eu queria mesmo. Nunca cogitei a ideia de mudar para a área técnica, como muitas pessoas tentam; nunca tive pavor de escola, nunca pensei: 'ah, eu não vou, não quero isso, não, quando terminar meu curso, eu não vou para a sala de aula, vou fazer mestrado, vou fazer concurso'. Sempre vi como uma possibilidade, sim, ir para a sala de aula e lecionar, e o Pibid veio para confirmar isso para mim e para me proporcionar uma interação maior com a escola” (Clara, trabalhadora em outra área e aspirante ao mestrado em Química ).
}

Percebemos nos depoimentos dos ex-bolsistas uma valorização muito positiva de sua passagem pelo Pibid, expressada na ideia de que o programa os ajuda a fortalecer e a aprofundar sua formação como docentes, principalmente por meio do exercício da prática de ensino que, segundo eles, ainda é muito reduzida no currículo da licenciatura. Nesse sentido, estamos de acordo com a argumentação de Rossi (2013) de que o Pibid configura de fato um grande estímulo à docência. Essa mesma preparação para o exercício da docência possibilitada pelo Pibid é destacada pelos egressos e contribui, indiretamente, para a opção preferencial pela educação permanente em cursos de mestrado em Química ou em área correlata, pois, na condição de professores, eles se percebem "prontos", porém, como químicos, falta-Ihes alguma coisa que eles começam a buscar na pós-graduação. Junto com essa avaliação positiva, surge algo que merece atenção, pois se relaciona com a exposição dos licenciandos à realidade da educação básica pública 
brasileira e que também contribui para as escolhas profissionais dos ex-bolsistas, como se observa no depoimento de Ana:

“E também outra questão: com a vivência no Pibid, pude perceber que há muitos professores desacreditados da educação, e parece que eles acabam nos contagiando em relação a isso. Não quero ficar em um ambiente assim, que não me agrada e não me faz bem".

Sua determinação vem replicar aquilo já observado por Rossi (2013) quanto à exposição dos licenciandos à realidade da educação pública brasileira.

Durante a análise dos dados por meio do modelo da Teoria Fundamentada, o desenho de diagramas contribuiu com o processo de codificação, o qual, por sua vez, ajudou a identificar a categoria central (core category) nesta pesquisa. O diagrama que representa a proposição deste estudo está representado pela Figura 1, que exibe a organização hierárquica das categorias e identifica a categoria central:

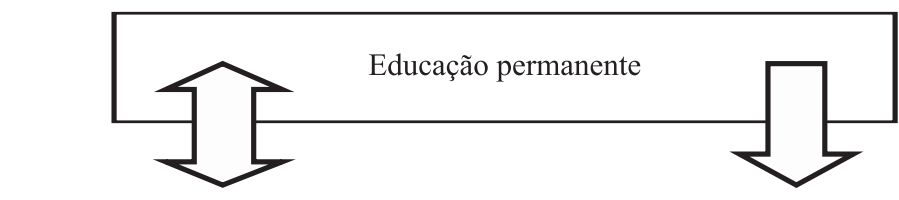

Formação como pesquisador

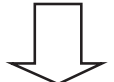

Preferência pela pesquisa química

Fonte: elaboração dos autores
Atuação como docente

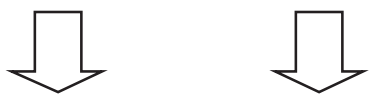

Um projeto Um projeto para o futuro alternativo

Figura 1. Concepções de ex-bolsistas Pibid sobre sua trajetória profissional 


\section{Considerações finais}

Por não se tratar de pesquisa realizada com uma amostra estatística, os dados deste estudo devem ser tomados com cautela ao dimensionar seus resultados em relação ao Pibid e à licenciatura em Química da Uesb. O contraste com a trajetória profissional de egressos do curso que não tenham sido bolsistas do Pibid, por exemplo, poderia complementar a pesquisa, pois possibilitaria averiguar o peso de certos fatores mencionados pelos ex-bolsistas na definição de suas trajetórias e que são compartilhados por todos os egressos. Nos depoimentos dos ex-bolsistas, o curso de licenciatura aparece com certas insuficiências no que se refere ao preparo dos professores, porém mesmo aqueles que decidem optar pelo mestrado em Química ou em área correlata como formação complementar afirmam buscar nesse mestrado algo que faltou na formação inicial, mas que deveria ter estado presente. Assemelham-se, nesse caso, às características do curso de História investigado por Amorim (2014), cujos egressos apontam carências tanto na formação do licenciando quanto na do pesquisador.

Seria ingenuidade de nossa parte não notar nos depoimentos dos ex-bolsistas a menção ao exercício da docência como um projeto para o futuro em universidades e institutos federais de educação, instituições em que as condições do trabalho docente são reconhecidamente superiores àquelas encontradas na maioria das escolas brasileiras, especialmente as públicas. Ao expor para os estudantes da licenciatura esse panorama de modo mais aprofundado, o Pibid corre até o risco de contribuir para que os bolsistas desistam de optar pela educação básica, como foi possível verificar no caso de uma dos ex-bolsistas. Aqueles que afirmam desejar ensinar expressam esse desejo como um projeto para o futuro ou apenas como uma alternativa para o presente, o que pode ser mais um indício da crise na educação brasileira, que apresenta sérias dificuldades em atrair profissionais para o exercício do magistério (FARIA FILHO, 2014).

Embora não se possa afirmar que o contexto acadêmico particular deste estudo apresente uma preponderância da pesquisa em Química sobre a formação docente, a existência do curso de 
mestrado em Química e as possibilidades que essa modalidade de formação permanente oferece aos egressos da licenciatura exercem uma atração muito forte. Não se trata, de acordo com eles, de atribuir um status maior a uma função do que a outra, mas de diversificar a sua própria formação, o que, por sua vez, possibilita atuação em ocupações diferentes. Esse interesse se manifesta neles como gosto e realização pessoais, como a expressão de uma autêntica inclinação que se ajusta a sua personalidade, oportunizando uma modulação de si coerente com a fluidez dos tempos contemporâneos.

O desenho metodológico adotado permitiu a compreensão das iniciativas dos ex-bolsistas com respeito a suas trajetórias profissionais e por que, para eles, o exercício docente é projetado para o futuro ou como uma alternativa, bem como do papel que a formação permanente assume para suas perspectivas pessoais e profissionais. Este estudo conduz a uma indagação sobre a ação do Pibid em contextos sem a presença de mestrados em Química ou em áreas correlatas no que se refere à trajetória profissional dos egressos e também o contraste com egressos que não tenham participado do programa.

As contradições levantadas nesta pesquisa em relação à influência do Pibid e à trajetória profissional dos egressos que foram bolsistas do programa levam à reflexão sobre a tão discutida qualidade da educação básica. A formação docente tem sido apontada como um dos fatores que contribuem para essa qualidade na educação, e o Pibid surge como uma política de indução de uma melhor formação de professores. Entretanto, como afirma Faria Filho (2014, p. 95), "a formação de professores é uma das mais baratas das políticas de educação, mesmo quando vêm acompanhadas de bolsas", e as pesquisas sobre formação e carreira docente indicam que o problema da atratividade da profissão "não é de um curso nem de uma universidade, mas da cena educacional contemporânea brasileira" (AMORIM, 2014, p. 55). Certas tensões resultantes da experiência de ser bolsista Pibid e a escolha pelo magistério na área de Química no contexto atual deslizam pelas vozes desses egressos, e elas demandam um olhar mais atento por parte de todos aqueles envolvidos com a formação de professores.

Recebido em 20/01/2015

Aprovado em 11/03/2015 


\section{Referências}

AMORIM, M. A. Quem ainda quer ser professora? A opção pela profissão docente por egressos do curso de história da UFMG. Educação em Revista, v. 30, n. 4, p. 37-59, 2014.

BAUMAN, Z. Modernidad líquida. Buenos Aires: FCE, 2006.

. Entrevista sobre la educación. Desafíos pedagógicos y modernidade líquida. Revista Propuesta Educativa, v. 16, n. 28, p. 7-18, 2007.

BRASIL. Lei n 12.796/2013, de 04 de abril de 2013. Diário Oficial [da] República Federativa do Brasil, Poder Executivo, Brasília, DF, 05 de abril de 2013. Seção 8, Artigo 62, p. 5.

Lei $n^{\circ}$. 13.005, de 25 de junho de 2014. Diário Oficial [da] República Federativa do Brasil, Poder Executivo, Brasília, DF, 26 de junho de 2014, 2014. Seção 1, Artigo 5, p. 4.

Ministério da Educação. Conselho Nacional de Educação.

Diretrizes curriculares nacionais para os cursos de química. Brasília: MEC/CNE, 2001.

CHARMAZ, K. A construção da teoria fundamentada: guia prático para análise qualitativa. Porto Alegre: Artmed, 2009.

CLIIMACO, J. C.; NEVES, C. M.; LIMA, B. F. Ações da CAPES para a formação e a valorização dos professores da educação básica do Brasil e sua interação com a pós-graduação. RBPG, Brasília, v. 9, n. 16, p. 181-209, 2012.

DELEUZE, G. Conversações: 1972-1990. 2. ed. São Paulo: Editora 34, 2010.

DUSSEL, I. Impacto de los cambios en el contexto social y organizacional del oficio docente. In: FANFANI, E. T. (Comp.). El oficio de docente: vocación, trabajo y profesión en el siglo XXI. Buenos Aires: Siglo XXI, 2006. p. 143-173. 
FARIA FILHO, L. M. A Universidade e a formação de professores: uma discussão necessária. In: SOUZA, J. V.; DINIZ, M.; OLIVEIRA, M. G. (Orgs.). Formação de professores (as) e condição docente. Belo Horizonte: Editora UFMG, 2014. p. 90-97.

GATTI, B.A.; BARRETO, E. S. (Coord.). Professores do Brasil: impasses e desafios. Brasília: UNESCO, 2009.

GLASER, B. G.; STRAUSS, A. L. The discovery of Grounded Theory: strategies for qualitative research. Chicago: Aldine, 1967.

LAPERRIÈRE, A. A teorização enraizada (grounded theory): procedimento analítico e comparação com outras abordagens similares. In: POUPART, J. et al. A pesquisa qualitativa: enfoques epistemológicos e metodológicos. 2. ed. Petrópolis: Vozes, 2010. p. 353-385.

OLIVEIRA, M. G. O PIBID-FAE/UESB e os processos de significação da prática docente. RBPG, Brasília, Suplemento 2, v. 8, p. 469-485, 2012.

ROSA, M. I et al. Formação de professores de química na perspectiva da cultura: reflexões sobre a noção de identidade profissional. In: ROSA, M. I.; ROSSI, A. V. Educação química no Brasil: memórias, políticas e tendências. Campinas: Átomo, 2008. p. 145-159.

ROSSI, A. V. O Pibid e a licenciatura em química num contexto institucional de pesquisa química destacada: cenário, dificuldades e perspectivas. Química Nova na Escola, São Paulo, v. 35, n. 4, p. 255-263, 2013.

SÁ, L. P. Narrativa autobiográfica de estudantes de Química: reflexões sobre a atividade docente. Revista Electrónica de Enseñanza de las Ciencias, v. 8, n. 2, p. 617-627, 2009.

. Narrativas centradas na contribuição do Pibid para a formação inicial e continuada de professores de Química. Química Nova na Escola, São Paulo, v. 36, n. 1, p. 44-50, 2014.

SCHNETZLER, R. P. O professor de ciências: problemas e tendências de sua formação. In:SCHNETZLER, R. P.; ARAGÃO, R. M. Ensino de ciências: fundamentos e abordagens. Campinas: Unimep/Capes, 2000. p. 12-41. 
SCHWARTZMAN, S.; CASTRO, M. H. A trajetória acadêmica profissional dos alunos da USP. Núcleo de Pesquisas sobre Ensino Superior da Universidade de São Paulo - Nupes. Documento de Pesquisa 2/91, 26 p., 1991. Disponível em:<nupps.usp.br/downloads/docs/dt9102.pdf>. Acesso em: 27 nov. 2014.

SILVA, M. G.; MARTINS, A. F. Reflexões do Pibid-Química da UFRN: para além da iniciação à docência. Química Nova na Escola, São Paulo, v. 36, n. 2, p. 101-107, 2014

SONEIRA, A. J. La Teoría Fundamentada en los Datos (Grounded Theory) de Glaser y Strauss. In: GIALDINO, I. V. (Coord.). Estrategias de investigación cualitativa. Barcelona: Gedisa, 2007. p. 153- 174.

STRAUSS, A.; CORBIN, J. Pesquisa qualitativa: técnicas e procedimentos para o desenvolvimento de teoria fundamentada, 2. ed. Porto Alegre: Artmed, 2008.

TOZZI, M. O que é a Grounded Theory? Metodologia de pesquisa e de teoria fundamentada nos dados. Petrópolis: Vozes, 2011.

TOYOS, F. T. D. Los docentes universitários y su concepción sobre el aprendizaje, la autorregulación y la personalización educativa. Un análisis desde la teoría fundamentada. Forum: Qualitative Social Research, v. 15, n. 2, 2014. Disponivel em <http://www.qualitativeresearch.net/>. Acesso em: 8 mar. 2015.

WEBER et al. A percepção dos licencia(n)dos em química sobre o impacto do Pibid em sua formação para a docência. Química Nova na Escola, São Paulo, v. 35, n. 3, p. 189-198, 2013. 